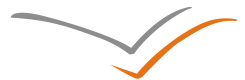 \\ VERSITA

\section{INTEGRATING MULTIPLE INTELLIGENCES IN TEACHING ENGLISH AS A FOREIGN LANGUAGE- SEEU EXPERIENCES AND PRACTICES}

\author{
Elena Spirovska, PhD \\ Language center, Seeu \\ Email: e.spirovska@seeu.edu.mk
}

DOI: $10.2478 /$ seeur-2013-0002

\begin{abstract}
The purpose of this article is to discuss the Theory of Multiple Intelligences and to answer the question of appropriateness of the MI theory in the field of foreign language teaching. The paper also exemplifies the adaptation of the theory in the context of teaching English as a foreign language and foreign language teaching and learning in general by describing a set of activities and a lesson plan using the MI approach. The article reviews the types of intelligences described and defined by Howard Gardner and authors who followed and revised the theory in terms of language teaching. In addition, the article discusses the different modes of application of the theory of Multiple Intelligences in language teaching with young adults and adult learners of foreign languages. The article proceeds by grouping and listing possible activities and tasks which are appropriate for language learners with different sets of abilities or intelligences. In addition, the article provides a brief summary of the potential issues recommendations and conclusions regarding the implementation of theory of Multiple Intelligences and provides a sample lesson plan which provides activities and language learning tasks for the majority of intelligences defined.
\end{abstract}

Key words: multiple intelligences, MI theory, language learning, language teaching. 


\section{Introduction}

It is very difficult to define the meaning of the word intelligence and the characteristics of intelligence. It is also challenging to measure intelligence and determine how intelligent we are. The debates on the appropriateness of IQ and the limitations of IQ testing are still in progress. According to Gardner (1983), the definition of intelligence in the Western society is very narrow. In terms of IQ tests, he suggested that the tasks they incorporate are in favour of educated individuals who have extensive educational background and are accustomed to testing. In 1983, Gardner developed the theory of Multiple Intelligences. Gardner introduced the concept that one intelligence only does not exist. Instead, he posited that individuals have several different intelligences. Initially, Gardner defined and compared seven different categories of aptitudes and capabilities and referred to them with the term intelligences. According to Gardner, every individual has all intelligences, but not to unified degrees. Gardner (1991), in Currie (2003) summarizes his theory of Multiple Intelligence as follows:

I have posited that all human beings are capable of at least seven different ways of knowing the world -- ways that I have elsewhere labeled the seven human intelligences. According to this analysis, we are all able to know the world through language, logical-mathematical analysis, spatial representation, musical thinking, and the use of the body to solve problems or to make things, an understanding of other individuals, and an understanding of ourselves. Where individuals differ is in the strength of these intelligences -- the so-called profile of intelligences -- and in the ways in which such intelligences are invoked and combined to carry out different tasks, solve diverse problems, and progress in various domains.

The purpose of this paper is to present and describe the types of intelligences defined by Gardner and the applicability of the theory of Multiple Intelligences within the framework of teaching foreign languages. In terms of foreign language teaching and language learning, we need to remember that every individual can develop all seven intelligences: linguistic, logical -mathematical, spatial, bodily kinaesthetic, musical, interpersonal and intrapersonal intelligence. This means that we can help our students develop the intelligences necessary for any content area learning, language learning included. 


\section{Theory of multiple intelligences}

According to the Theory of Multiple Intelligences and Howard Gardner, the different types of intelligence can be defined and described as follows:

\section{Linguistic Intelligence}

Linguistic intelligence can be defined as ability to use language and words in an effective manner, regardless of whether the medium of expression is a written or spoken. Gardner (1993) exemplifies the type of people who are linguistically intelligent as poets. He describes his personal experience with linguistically intelligent people as follows:

I once took a course with Robert Lowell, and he would read a student's poem and he would comment very penetratingly about the poem. He would pick out a particular word in the poem and he would do something that absolutely astounded me. He would take that word and tell you how every major poet in the English language had used that word over the centuries. His mind was organized in that way. I venture to say that if everyone in this room, for the rest of his life, tried to organize his mind in this way, he would not be able to succeed. It would be very hard anyway. (p.27)

People who have the linguistic intelligence can also understand the linguistic messages from other people. According to Torresan (2010, p.13):“One of the main components of the linguistic intelligence is semantics, along with phonology, syntax and pragmatics. Christison (1996) adds that people who can be described as linguistically intelligent can effectively talk about language, persuade others or convey information. In terms of foreign or second language learning classrooms, it can be noted that students with predominant linguistic intelligence can easily express themselves in a spoken or written manner, can easily match synonyms, comprehend a reading text or write a paragraph.

\section{Logical-Mathematical Intelligence}

Logical- mathematical intelligence can be described as ability to reason and use numbers effectively. In addition, people who posses this type of intelligence can successfully carry out different mathematical operations, categorize and classify objects or phenomena easily, sequence events in order, calculate and generalize. Torresan (2010, p.13) poses: "In this kind of intelligence, the processing of long chains of reasoning plays a central role. It appears very early in life: the child can make observations about objects that are no longer in his presence, therefore he is able to manipulate them, he can intuitively reason about their number, perform arithmetic operations, and as he grows older, he can replace them with increasingly complex symbols and functions". Students who have this ability, in terms of second or foreign language learning, can sequence described events in chronological order, classify language items easily, or successfully manage to work on problem-solving activities.

\section{Visual-Spatial intelligence}


Gardner (1983, 1993) described spatial intelligence as ability to imagine or form an image which represents the spatial world. According to Torresan (2010, p.14): "Spatial intelligence refers to the ability to mentally reconstruct or modify the disposition of objects in space, concluding with the representation of ideas. People who are spatially intelligent are also perceptive of forms, shapes as well as colors. According to Christison (1996) spatial intelligence also involves the skill to graphically represent visual or spatial ideas. People with this kind of intelligence are often architects and designers. In terms of foreign language teaching and learning, different tasks such as pictures, concept mapping or diagrams successfully help the students who possess visual-spatial intelligence.

\section{Bodily Kinesthetic Intelligence}

According to Gardner (1983, 1993), bodily kinesthetic intelligence is the ability to use the body or a body part in order to successfully perform a task or solve a problem. This type of intelligence is used by dancers, athletes or surgeons, as well as craftspeople. The bodilykinesthetic intelligence comprises two skills. One is the control of bodily and physical movements (sports and dance). The other is the ability to manipulate objects and work with hands, for instance sculpting and crafts. A person with this kind of intelligence has physical skills which involve coordination, flexibility, speed, balance, etc. Students whose predominant intelligence is bodily kinesthetic learn foreign languages effectively by games, miming out different actions, drama, role plays and other activities which require bodily movements.

\section{Musical Intelligence}

Musical intelligence can be described as sensitivity to rhythm and melody. According to Christison (1996), musical intelligence can be described as global understanding of music. Torresan (2010) describes musical intelligence as:

Musical intelligence allows us to think in rhythmic, cadenced terms, and to enjoy and compose melodies. Of all intelligences, it is the most precocious and is among those where the genetic patrimony has the strongest influence. It includes aspects (intonation and timbre) related to auditory perception, along with other aspects (rhythmic organization) that are independent from it. (p.14)

In foreign language learning context, learning for students with this particular type of intelligence can be fostered by using music, songs or rhymes, as well as tongue twisters.

\section{Interpersonal intelligence}

According to Gardner (1983, 1993), interpersonal intelligence can be described as ability to understand and to empathize with other person's emotions. This type of intelligence also involves the ability to understand the motivations and intentions of others. According to Christison (1995), this type of intelligence can be defined:'Interpersonal intelligence also includes the ability to respond effectively to other people in some pragmatic way, such as 
influencing them to follow a certain action". In a language learning classroom, learners who posses this type of intelligence stand out in analyzing characters, retelling stories from a different points of view or discussing different opinions.

\section{Intrapersonal intelligence}

Intrapersonal intelligence can be defined as the ability to understand oneself, your own wishes, intentions, motivations and feelings. Gardner (1983) believes that this type of intelligence is really important and at the same time, comprises the knowledge of other intelligences that people have or do not have. Torresan (2010) states the following about intrapersonal intelligence:

Contrary to common belief, the knowledge of oneself does not exclude consideration of the relationship one has with others. In other words, the more the person discovers in the experiences of the other a motive for self-reflection, the more the intra-personal intelligence is developed. Both kinds of intelligences have their roots within family relationships in the early infancy of the child: on the one hand, the bond and the sense of separation the child has with his mother, on the other hand, his observations of the motivations, the intentions, and the natures of people around him (p.16).

Foreign language learners with predominant intrapersonal experience excel in activities which require self analysis. For instance, writing reflections or journal keeping can effectively cater for this type of intelligence.

Later, in an interview with Checkley (1997, in Bas, 2008), Gardner added and described two additional types of intelligence. They are referred to as naturalistic intelligence and existential intelligence. Naturalistic intelligence can be described as the ability to recognize and classify animals and plants. Existential intelligence can described as sensitivity to the processes of existence. Torresan (2010) defines this type of existence as follows:

The existential intelligence is the human response to the limits and the processes of existence. Its uniqueness is the capacity to ask fundamental questions: Who are we? Where do we come from? Where are we going? What is the meaning of life? Where does love come from? Where does creativity come from? (p.17)

Existential intelligence is the latest one to be described by Howard Gardner and at this point, it is not very specifically defined.

\section{Application of multiple intelligences theory on language teaching and learning}

According to Christison \& Kennedy (1999), teachers can focus on four different modes in order to implement the theory of Multiple Intelligences in EFL/ESL classroom and with young adults or adult learners. Christison (1999) offers several suggestions for how to approach the theory of Multiple Intelligences in the classroom, including: 
1. As a tool to help students develop a better understanding and appreciation of their own strengths and learning preferences. According to Christison \&Kennedy (1999), the above mentioned can be done by taking an inventories or surveys which might help the students to define their predominant type of intelligence. According to Christison, different language tasks and activities can be created in order to cater for the needs of multiple intelligences and the needs of the language learners.

2. As a tool to develop a better understanding of learners' intelligences and awareness of intelligence diversity within the classroom. According to Christison \& Kennedy (1999), the theory of Multiple Intelligences raises the awareness of teachers of the diversity of their students' potentials and skills and different ways the students' demonstrate their knowledge and understanding of the material.

3. As a guide to provide a greater variety of ways for students to learn and to demonstrate their learning and understanding. According to Christison \& Kennedy (1999) raising students' awareness of their strengths and weaknesses can make them more responsive to a variety of learning activities and tasks which might be unfamiliar to students based backgrounds and experiences.

4. As a guide to develop lesson plans that address the full range of learner needs. Lesson plans based on the theory of Multiple Intelligences might combine different language learning tasks and activities which, according to Christison\& Kennedy(1999) would not aim to use specific intelligences but to enable the learners to use the best way for them to acquire that knowledge.

The primary importance of the implementation of theory of multiple intelligences is that it is possible to give students a chance to use their predominant strengths and capabilities in order to foster learning. Currie (2002) emphasizes that if teachers are acquainted with the intelligence profiles in a class, they can adapt or develop a variety of activities which can use students' intelligence to enrich the learning environment. In addition, Currie(2003) adds that: "Teachers should not only observe the highest scores registered by each of their students in order to discover appropriate entry points for effective learning, they should also examine the lowest scores obtained by their students in order to discover which areas of intelligence need to be developed during the course". Thus, by observing the highest and the lowest scores, the teachers have an accurate picture of students' skills, capabilities and learning preferences. On the other hand, they also have the opportunity to predict the difficulties and plan the activities in order to develop the intelligences which are not strongly emphasised. According to Arnold \& Fonseca (2004, p.125) : "With MIT applied in the language classroom, teachers are better able to tap into the areas of personal meaningfulness of their students since they are recognizing the differences inherent in the students and putting individuals with their different ways of learning where they belong, back at the centre of the learning process. "

In terms of teaching English as a foreign language, there is a wide range of activities which might be used in order to cater for the different types of intelligences and applied in EFL/ESL classroom. These activities can be grouped as follows: 
Linguistic Intelligence: reading a story, choosing appropriate word to fill in a gap in a sentence, choosing an appropriate synonym or antonym for a given word, answering multiple questions related to a text.

Logical Mathematical Intelligence: sequencing events in a chronological order, finding logical errors, presenting timelines of events presented in a story or a text, jigsaw puzzles and games, concept maps.

Bodily Kinesthetic Intelligence: drawing, coloring, mime, dramatization, making models of objects and using realia (real objects), games.

Visual Spatial Intelligence: drawing diagrams, concept maps, matching pictures with words, describing pictures or images.

Musical Intelligence: songs, tongue twisters, rhymes, playing songs in order to introduce a topic or analyze the lyrics, transforming lyrics into a text.

Interpersonal Intelligence: analyzing a character, reflections on characters and their actions or motivation, analyzing or retelling/rewriting a text from another's character point of view, group work.

Intrapersonal Intelligence: journal keeping, activities in order to elicit personal experiences (reflections, discussions and sharing personal experiences).

Naturalistic Intelligence: comparison between a novel and a film, news broadcasted by two different resources, categorizing, analyzing settings, field trips and projects.

A lesson plan which includes a variety of different activities catering for the majority of intelligence types can be seen under appendix 1. The author's aim was to present a lesson plan appropriate for a group of language learners of intermediate or lower intermediate level of English. In addition, the author intended to describe the activities and indicate which intelligence type is catered for with each activity described.

\section{Issues, recommendations and conclusions}

The possibilities of using Multiple Intelligences theory in a foreign language classroom are numerous. Experimental research and pilot studies (Haley, 2004) have shown that the theory of Multiple Intelligence has a potential to create a positive influence on both language learners and language teachers. The results of the research indicated that teachers were influenced by Multiple Intelligence theory approach. However, both positive and negative impacts of MI theory application need to be analyzed.

Among the issues related to Multiple Intelligence theory and language teaching and learning is that presently there are only a few tests which can be used to analyze one's MI profile and measure the different intelligences separately. In addition, there is little empirical research 
conducted to this point in terms of Multiple Intelligence testing in general. Also, it can be argued that testing which measures each intelligence separately can result in labeling and furthermore, discrimination, especially in cultures or teaching environments which prefer one type of intelligence to another (for instance logical mathematical to bodily kinesthetic).

Another issue is related to instructors' preparedness to use MI theory in the classroom. Trainings and workshops which will raise the awareness of the teachers of the Multiple Intelligences are needed prior to practical implementation of the MI theory. The trainings are also necessary in terms of analyzing the practical application and implications of MI theory on language learning and teaching. Therefore, these trainings may focus on activities and practical tasks which originate from MI theory.

Furthermore, the practical application of MI theory requires a large amount of preparation, especially in terms of choosing and adapting a variety of activities which will correspond to various MI profiles in the classroom, which might be time consuming and overwhelming. This issue can be addressed via careful planning and analyzing the language teaching and learning context, as well as the given objectives for a specific lesson, which facilitates planning and activity design or adaptation.

In addition, implementation of MI theory has an impact on assessment. It can be argued that learners with various MI profiles and various learning preferences need to be assessed accordingly and in ways which correspond to their diverse MI profiles. One way to address this issue is to use more forms of assessment, possibly including projects which will give a chance to learners to complete them according to their own preferences and learning styles, as one assessment criteria. These projects might include poster presentations or oral presentations, role plays, journals or debates.

However, the benefits of using the MI approach in language teaching cannot be neglected. In terms of teaching, the MI theory raises the awareness of language teachers of the diversity of potentials which exist in a language learning class and the different ways that students learn. Also, teachers have the option of analyzing their own profile according to Multiple Intelligences theory, which will enable them to link their own experiences as learners with their current teaching situation. Therefore, their role is extended beyond teaching; they also influence the lesson development as well as curriculum development.

In addition, the MI theory offers a huge variety of ideas regarding activities and lesson planning. As a result, it gives the educators an opportunity to reflect on the activities to be used in class and to plan a variety of different activities which might be used in order to raise the effectiveness of the lesson. Thus, they contribute not only to the development of linguistic skills of their learners, but also to the overall learning abilities and even personal skills (for instance, ability to communicate effectively or to develop empathy). As a result, educators have the opportunity to be "contributors to the overall development of students' intelligences" (Christison 1999, 12). 
Furthermore, the MI theory promotes the learner-centeredness in a language classroom, by emphasizing language learners' strengths and needs. On the other hand, the language learners are given the opportunity to consider the activities and language learning tasks which suit their strengths as learners, thus taking their interests into account and motivating them additionally. Both of these aspects foster learning and provide benefits for educators and students.

It can be concluded that the application of theory of Multiple Intelligences in foreign language teaching and learning can be valuable and positive experience for both teachers and learners. 


\section{References}

1. Arnold, J. \& Fonseca, C. (2004). Multiple Intelligence Theory and Foreign Language Learning:

2. A Brain-based Perspective, International Journal of English Studies (IJES).Vol.4, No 1 .

Retrieved on May 15, 2013 from http://revistas.um.es/ijes/article/view/48141/46121

3. Bas, G. (2008), Integrating Multiple Intelligences in ESL/EFL Classrooms, The Internet TESL Journal, Vol. XIV, No. 5.

Retrieved on May 14, 2013 from:

http://iteslj.org/Techniques/BasIntegratingMultipleIntelligences.html

4. Christison, M.A. (1996). Multiple Intelligences and Second Language Learners. The Journal of the Imagination in Language Teaching and Learning, Vol. III-1995-1996. Retrieved from http://www.njcu.edu/cill/vol3/christison.html

5. Christison, M.A. \& Kennedy, D. (1999). Multiple Intelligences: Theory and Practice in Adult ESL. Key Resources.

Retrieved from http://www.cal.org/adultesl/resources/digests/multiple-intelligences.php

6. Currie,K.L.(2003).Multiple Intelligence Theory and the ESL Classroom -- Preliminary Considerations, Internet TESL Journal, Vol. IX, No. 4 Retrieved on May 25, 2013 from http://iteslj.org/Articles/Currie-MITheory.html

7. Gardner H. (1983). Frames of Mind: The Theory of Multiple Intelligences. New York: Basic Books.

8. Gardner H. (1993). Multiple Intelligences: The Theory in Practice. New York: Basic Books

9. Halley, M.H (2004). Learner-Centred Instruction and the Theory of Multiple Intelligences with Second Language Learners. Teachers College Record, Volume 106, Number 1, pp163-180.

Retrieved from: http://gse.gmu.edu/assets/docs/forms/mirs/teachers_college_record-learner-

centered_instruction_and_the_theory_of_multiple_intelligences_with_second_langua ge learners.pdf

10. Torresan, P. (2010). The Theory of Multiple Intelligences and Language Teaching. The Documents on Language Acquisition and Learning.

Retrieved fromhttp://lear.unive.it/bitstream/10278/2303/1/Nr.\%206\%20versione\%20inglese.pdf 


\section{Appendix 1}

The purpose of this lesson plan is to present teaching of a topic (part of Level 3 Basic Skills English curricula) with a variety of activities which are developed according to Multiple Intelligences Theory. The activities have the aim to target the diverse skills commonly seen in a foreign language classroom and to enable the students to focus on the activities and tasks which are most beneficial for them.

Lesson plan:

In this lesson, students acquire the vocabulary related to food preparation and practice describing ingredients in different dishes.

1. Students are given a set of pictures showing people from different countries who prepare food in different ways (frying, barbeque), accompanied by a set of different verbs. Students are asked to focus their attention first on the photographs and afterwards to match the pictures with the list of verbs. They write captions on each photograph, for instance: Frying fritters in Brazil.

Intelligence catered for: linguistic, visual-spatial.

2. Students are divided into pairs and asked to describe each picture to a partner. Apart from describing a picture, they also talk about their personal preferences and which food they would like to try and explain why.

Intelligence catered for: linguistic, intrapersonal, and interpersonal.

3. Students are given a set of definitions, for instance: Cook food in hot oil. They are asked to match the given definitions with cooking verbs.

Intelligence catered for: linguistic, logical mathematical.

4. Students are given a recipe. The instructions in the recipe are shuffled. Students are asked to read the instructions and put them in the correct order. They check with a partner.

Intelligence catered for: linguistic, logical-mathematical.

5. Teacher distributes lyrics of the song: How do you like your eggs in the morning (Dean Martin and Helen O'Connell) with words (fried, boiled) deleted from the lyrics. Students are asked to complete the lyrics and fill in the gaps.

Intelligence catered for: linguistic, musical.

6. Students are given pictures of different salads. They listen to an excerpt and one recipe. They guess which of the salads presented on the pictures is described in the recipe. 
Intelligence catered for: linguistic, visual-spatial, and naturalistic.

7. Students are given set of verbs. They choose one and think of the way to act it (for example peel a potato). Individual students are asked to come in front of the class and mime out the verb. The rest of the students guess the verb.

Intelligence catered for: linguistic, bodily-kinesthetic.

8. Students work with a partner. They think of some food or drink they know how to prepare. They prepare a list of necessary ingredients.

Intelligence catered for: linguistic, logical-mathematical, and naturalistic. 